Z Rheumatol 2018 $77: 80$

https://doi.org/10.1007/s00393-017-0416-z

Online publiziert: 15. Januar 2018

(c) Springer Medizin Verlag GmbH, ein Teil von Springer Nature 2018

CrossMark

Klaus L. Schmidt

Bad Nauheim, Deutschland

\title{
Kommentar und Ergänzung
}

\section{Leukopenien und Agranulozytosen unter Antirheumatikatherapie bei HLA-B27- positiven Patienten}

B27 [2], und G.E. Ehrlich (Philadelphia) berichtete in einem persönlichen Brief ebenfalls von HLA-B27-positiven Agranulozytosen [3].

Die Entdeckung, dass bei HLA-B27positiven Patienten mit rheumatoider Arthritis (nicht mit einer sog. Spondarthritis!) und offenbar auch bei Nicht-Rheumatikern dieses Antigen ein Risikomarker ist für eine medikamentös ausgelöste Agranulozytose, ist in Vergessenheit geraten. Das Levamisol - ursprünglich ein Anthelminthikum aus der Veterinärmedizin und als der erste sog. „Immunmodulator" eine interessante Substanz - kam als Antirheumatikum nicht auf den Markt. Es erlangte aber in jüngster Zeit wieder eine beklemmende Aktualität, weil Kokain-„User“ in den USA und England das Kokain - offenbar um eine Wirkungsverlängerung zu erzielen - mit Levamisol strecken. Prompt traten schwere Agranulozytosen auf. Ob diese Kokainverbraucher HLA-B27-positiv waren, ist natürlich noch nie untersucht worden. Auch gibt es leider keine echten epidemiologischen Studien, wie hoch tatsächlich die Rate an HLA-B27 bei medikamentös ausgelösten Agranulozytosen ist. Dass dieses Antigen aber ein Risikoanzeiger für eine medikamentös induzierte Agranulozytose ist, kann wohl nicht mehr bezweifelt werden.

\section{Korrespondenzadresse}

Prof. Dr. K. L. Schmidt

Dürerstr. 2F, 61231 Bad Nauheim, Deutschland

Prof. Dr. Klaus L. Schmidt war Direktor der Klinikfür Rheumatologie, Physikalische Medizin und Balneologie der Justus-Liebig-Universität Gießen, Bad Nauheim.
Interessenkonflikt. K.L. Schmidt gibt an, dass kein Interessenkonflikt besteht.

\section{Literatur}

1. Schmidt KL, Mueller-Eckhardt C (1977) Agranulocytosis, levamisol, and HLA-B 27. Lancet II:85

2. Schmidt KL, Mueller-Eckhardt C, Breithaupt $\mathrm{H}$ (1978) HLA-B 27, antinuclear antibodies and drug-induced agranulocytosis. Klin Wochenschr 56:1189-1191

3. Ehrlich GE (1981) Persönlicher Brief an den Autor 